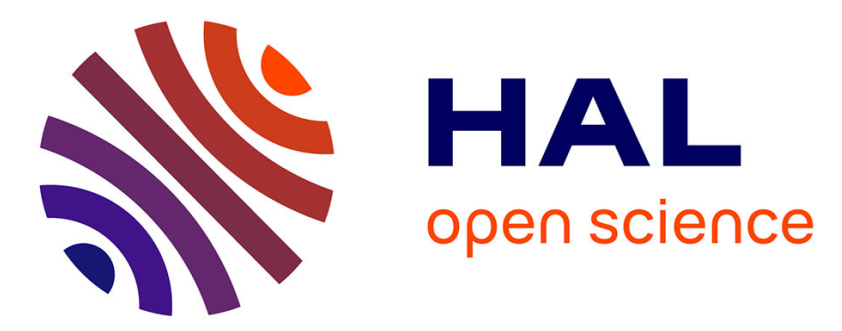

\title{
A Transmission Electron Microscopy study of composition in Si1-xGex / Si (001) quantum dots
}

Yidir Androussi, Tarik Benabbas, Slawomir Kret, Vincent Ferreiro, Alain Lefebvre

\section{- To cite this version:}

Yidir Androussi, Tarik Benabbas, Slawomir Kret, Vincent Ferreiro, Alain Lefebvre. A Transmission Electron Microscopy study of composition in Si1-xGex / Si (001) quantum dots. Philosophical Magazine, 2007, 87 (10), pp.1531-1543. 10.1080/14786430601055387 . hal-00513799

\section{HAL Id: hal-00513799 \\ https://hal.science/hal-00513799}

Submitted on 1 Sep 2010

HAL is a multi-disciplinary open access archive for the deposit and dissemination of scientific research documents, whether they are published or not. The documents may come from teaching and research institutions in France or abroad, or from public or private research centers.
L'archive ouverte pluridisciplinaire HAL, est destinée au dépôt et à la diffusion de documents scientifiques de niveau recherche, publiés ou non, émanant des établissements d'enseignement et de recherche français ou étrangers, des laboratoires publics ou privés. 


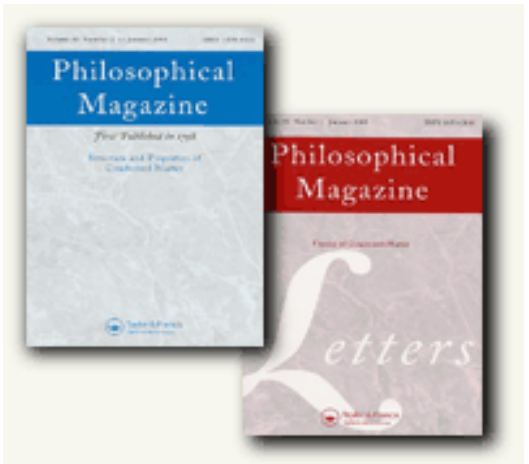

\section{A Transmission Electron Microscopy study of composition in Si1-xGex / Si (001) quantum dots}

\begin{tabular}{|r|l|}
\hline Journal: & Philosophical Magazine \& Philosophical Magazine Letters \\
\hline Manuscript ID: & TPHM-06-Jun-0217.R1 \\
\hline Journal Selection: & Philosophical Magazine \\
\hline Author: & 27-Sep-2006 \\
\hline Complete List of Authors: & $\begin{array}{l}\text { Androussi, Yidir; CNRS, LSPES UMR 8008 } \\
\text { Benabbas, Tarik; CNRS, LSPES UMR 8008 } \\
\text { Kret, Slawomir; Institute of Physics, Polish Academy of Sciences } \\
\text { Ferreiro, Vincent; CNRS, LSPES UMR 8008 } \\
\text { Lefebvre, Alain; CNRS, LSPES UMR 8008 }\end{array}$ \\
\hline Keywords: & quantum dots, transmission electron microscopy \\
\hline Keywords (user supplied): & chemical composition, displacement field \\
\hline \multicolumn{2}{|l}{} \\
\hline
\end{tabular}

\section{S ScholarONE \\ Manuscript Central}




\section{Y. ANDROUSSI ${ }^{1 *}$, T. BENABBAS ${ }^{1}$, S. KRET $^{2}$, V. FERREIRO $^{1}$ and A. LEFEBVRE \\ ${ }^{1}$ Laboratoire de Structure et Propriétés de l'Etat Solide (UMR CNRS 8008), Université des Sciences et Technologies de Lille, Bâtiment C6, 59655 Villeneuve d'Ascq cedex, France \\ ${ }^{2}$ Institute of Physics, Polish Academy of Sciences, Al. Lotnikow 32/46, 02-668 Varszawa, Poland}

*Tel: 00330320434966; Fax: 00330320436591

Email: ydir.androussi@univ-lille1.fr 


\title{
A Transmission Electron Microscopy study of composition in $\mathrm{Si}_{1-\mathrm{x}} \mathrm{Ge}_{\mathrm{x}} / \mathrm{Si}$ (001) quantum dots
}

\author{
Y. ANDROUSSI ${ }^{1 *}$, T. BENABBAS ${ }^{1}$, S. KRET $^{2}$, V. FERREIRO $^{1}$ and A. \\ LEFEBVRE $^{1}$ \\ ${ }^{1}$ Laboratoire de Structure et Propriétés de l'Etat Solide (UMR CNRS 8008), \\ Université des Sciences et Technologies de Lille, Bâtiment C6, 59655 \\ Villeneuve d'Ascq cedex, France \\ ${ }^{2}$ Institute of Physics, Polish Academy of Sciences, Al. Lotnikow 32/46, 02-668 \\ Varszawa, Poland
}

\begin{abstract}
A finite-element program has been developed to model strain relaxation in the case of epitaxial $\mathrm{Si}_{1-\mathrm{x}} \mathrm{Ge}_{\mathrm{x}} / \mathrm{Si}$ coherent quantum dots either with or without compositional inhomogeneities. The resulting elastic displacement fields are used to calculate the intensity of dynamical plan view TEM images of such quantum dots. Various types of linear or parabolic compositional inhomogeneities are studied. TEM images of quantum dots with such inhomogeneities are calculated as well as those of quantum dots with a homogeneous composition. They are then compared with experimental images. It is shown how the analysis of the main features of these experimental images (black/white lobes and moiré-like fringes) enables us to determine the conditions in which it is possible to distinguish quantum dots with a homogeneous composition from those with compositional inhomogeneity.
\end{abstract}

Keywords: Transmission electron microscopy; quantum dots; chemical composition; displacement field 


\section{INTRODUCTION}

Self-assembled quantum dots (QDs) in heteroepitaxial semiconductor systems have recently been an area of intense study because many electronic devices based on QDs have been theoretically proved to possess better electronic and optical properties than quantum-well devices. Knowing the structural parameters of QDs including the shape, size and chemical composition at different stages of QD island growth is thus important for understanding the structure-property relationship of the QDs as well as revealing information on QD growth mechanisms [1]. However, the accurate characterization of coherent islands is not trivial due to their small sizes and the coupling effects between composition and strain field. An additional complexity is that the island shape and composition are a function of substrate temperature (during growth), of coverage and of the type of crystal growth technique.

$\mathrm{Ge} / \mathrm{Si}$ (001), in particular, has served as a model system because it is a simple two-component system and due to the hope of combining these QDs easily with existing Si technology. Morphology evolution of uncapped QDs has been extensively investigated and it is reasonably well understood [2-4], but despite its impact on optical and electronic properties, island composition evolution is still in debate. The determination of local composition can be carried out with techniques that average over many islands. These include high resolution x-ray diffraction [5], x-ray anomalous scattering [6,7] and x-ray absorption fine structure [8]. Selective etching coupled with atomic force microscopy [9] and electron-microscope-based methods make it possible to measure composition variations throughout individual islands. These methods are scanning tunneling microscopy [10] and transmission electron microscopy (TEM) techniques including high resolution imaging combined with finite element analysis [11], electron energy loss spectrometry (EELS) [12-14] and xray energy dispersive spectrometry (EDS) [15-16]. For each of the above TEM studies, very thin cross-section specimens are required. However, it is difficult to prepare cross-section TEM specimens, especially for samples with low QD densities, and even then the section might include any part of the QD. As a result, there is an advantage in using plan-view samples. Besides, plan-view samples have a larger sampling region that provides a superior statistical basis and contrary to cross-section samples, the surface relaxation effects are negligible in them. That is why plan-view specimens have been successfully used to extract alloying information in $\mathrm{Si}_{1-\mathrm{x}} \mathrm{Ge}_{\mathrm{x}} / \mathrm{Si}$ QDs from diffraction contrast images [17].

It has been recently shown that information on the chemical composition of coherently strained islands can also be obtained by TEM when fringes - which we have called "moiré-like fringes"- are observed in plan-view images of $\operatorname{In}_{\mathrm{x}} \mathrm{Ga}_{1 \text { - }}$ ${ }_{x} A s / G a A s$ QDs [18-20]. The same type of fringes has also been observed in $\mathrm{SiGe/Si}$ QDs [21-22]. This paper is aimed at showing that these moiré-like fringes can be used to study the chemical composition of such QDs. Finite- 
element (FE) calculations are performed in order to take account of various complex compositional variations. It is then shown how the resulting strain fields (and consequently the compositional inhomogeneities) can be studied via the dynamical contrast of TEM plan-view images of QDs.

\section{EXPERIMENTAL PROCEDURE}

The growth of the self-assembled islands is carried out in an ultra-vacuum chemical vapor deposition growth chamber with silane and germane diluted in hydrogen used as precursors [23]. Four monolayers of Ge are deposited at 600 or $700^{\circ} \mathrm{C}$ on $\mathrm{Si}(001)$. Atomic force microscopy (AFM) experiments are carried out in air using a Nanoscope III Multimode microscope from Digital Instruments operating in the tapping mode. Integrated silicon tips with a radius of curvature of about $10 \mathrm{~nm}$ and cantilevers (model TSEP) with a nominal spring constant 30 $\mathrm{Nm}^{-1}$ are used. The $(512 \times 512$ pixels $)$ images are obtained with a $100 \times 100 \mu \mathrm{m}$ piezoelectric scanner and with a $0.4 \mathrm{~Hz}$ scanning frequency.

\section{[Insert figure 1 about here]}

The finite-element (FE) calculations are performed using a "home-made" program so as to calculate displacement fields $\mathbf{R}$ taking account of possible compositional variations in $\mathrm{Si}_{1-\mathrm{x}} \mathrm{Ge}_{\mathrm{x}} / \mathrm{Si}$ QDs. They are carried out in the case of lens-shaped domes (Fig. 1) with values of $b$ and $h$ as indicated in table 1 . The compositional variations are introduced by local variations of the elastic constants and for each finite element, a virtual thermal expansion coefficient is introduced so as to simulate a local lattice mismatch that will occur during the FE calculation by raising the temperature by $1 \mathrm{~K}$. The thermal expansion coefficient $\alpha$ has thus to fulfill the relation $\mathrm{a}(\mathrm{x})=\mathrm{a}(0)(1+\alpha \Delta \mathrm{T})$ where $\mathrm{a}(\mathrm{x})$ is the bulk-material lattice parameter corresponding to the Si concentration $\mathrm{x}$ of the finite element.

[Insert table 1 about here]

Plan-view TEM thin foils are mechanically thinned from the substrate side by wedge polishing. TEM images are taken with a Philips CM30 microscope (operated at $300 \mathrm{kV}$ ) and directly captured with a cooled slow-scan chargecoupled device (CCD) Gatan camera.

The two-beam dynamical TEM contrast of QDs is simulated by solving the Howie and Whelan equations based on the so-called column approximation [24]. The displacement field $\mathbf{R}$ is computed at equispaced points in the [001] direction by carrying out the Lagrange interpolation procedure on the data points provided by finite-element calculations. It should be noted that these calculations make it possible to readily vary the shape of the islands and their aspect ratio.

\section{RESULTS}


A bimodal dot distribution with square-based pyramids and domes is observed by atomic force microscopy at $700^{\circ} \mathrm{C}$ (see for instance both types of islands in Fig. 2) whereas only domes are observed at $600^{\circ} \mathrm{C}$. The average sizes of both types of islands are indicated in table 1 as a function of temperature. The aspect ratio $\rho=0.20 \pm 0.02$ was found to be constant for all the observed $D_{2}$ islands.

\section{[Insert figure 2 about here]}

The characteristics of plan-view dynamical TEM dark-field images of strained islands have been fully described in the case of coherently strained $\mathrm{In}_{\mathrm{x}} \mathrm{Ga}_{1-\mathrm{x}} \mathrm{As} / \mathrm{GaAs}[19,25]$ or $\mathrm{Si}_{1-\mathrm{x}} \mathrm{Ge}_{\mathrm{x}} / \mathrm{Si}$ islands [21,22]. They all exhibit a black/white contrast, as shown in Fig. 3 and 4 in the case of pyramids $(\mathrm{P})$ grown at $700^{\circ} \mathrm{C}$ and in the case of domes grown at $600^{\circ} \mathrm{C}\left(\mathrm{D}_{1}\right)$ or $700^{\circ} \mathrm{C}\left(\mathrm{D}_{2}\right)$. When the islands display a sufficiently high aspect ratio $(\mathrm{h} / \mathrm{b}>\sim 0.2)$, moiré-like fringes are found to be superimposed to the black/white contrast (see $\mathrm{D}_{2}$ domes in Fig. 4). This is fully consistent with what has been demonstrated in the case of $\mathrm{In}_{\mathrm{x}} \mathrm{Ga}_{1-\mathrm{x}} \mathrm{As} / \mathrm{GaAs}$ islands [19]. These images were obtained for QDs on the electron entrance surface, with a diffraction vector $\mathbf{g}=220$ parallel to the interface and with $\mathrm{w}_{\mathrm{g}}=\mathrm{s}_{\mathrm{g}} \xi_{\mathrm{g}}=-1.10 \pm 0.05\left(\mathrm{~s}_{\mathrm{g}}\right.$ is the deviation parameter and $\xi_{\mathrm{g}}$ the extinction distance). This negative value of $\mathrm{w}_{\mathrm{g}}$ was used because it was found to give the highest contrasts and because it was consistent with the general rules established by Katerbau [26] for lattice defects near the specimen surfaces. Following these rules, the contrast of such defects depends on the imaging mode (bright or dark field), on the defect position (near the electron entrance or the electron exit surface of the specimen) and on the sign of $\mathrm{w}_{\mathrm{g}}$. The various cases are summarized in table 2: for bright-field images, the contrast is reduced (enhanced) for $\mathrm{w}_{\mathrm{g}}<0\left(\mathrm{w}_{\mathrm{g}}>0\right)$ whatever the defect position. On the contrary, for dark-field images, the reduction (or enhancement) simultaneously depends on the sign of $\mathrm{w}_{\mathrm{g}}$ and on the defect position. There is thus an advantage to take darkfield images (rather than bright-field images) either with QDs near the electron entrance (with $\mathrm{w}_{\mathrm{g}}<0$ ) or near the electron exit surface (with $\mathrm{w}_{\mathrm{g}}>0$ ): in both cases, the contrast is enhanced for QDs whereas it is reduced for defects resulting from the specimen thinning on the opposite surface.

\section{[Insert figure 3 about here] [Insert figure 4 about here] [Insert table 2 about here]}

Uncapped $\mathrm{Si}_{1-\mathrm{x}} \mathrm{Ge}_{\mathrm{x}} / \mathrm{Si}$ islands grown either by molecular beam epitaxy or by chemical vapor deposition generally display aspect ratios inferior to $\sim 0.3$ and two types of compositional heterogeneities. In the first type, a diffuse interface with $\mathrm{Si} / \mathrm{Ge}$ mixing is observed, the island composition is homogeneous away from the intermixed interface and a laterally constant composition is maintained in the $\mathrm{r}$ direction $[7,13]$. In the second type, the islands contain a Si-rich core 
covered with a Ge-rich shell and the composition is not laterally constant $[6,17]$. It should be noted that a uniform composition has been found in low mismatch $\mathrm{Si}_{0.8} \mathrm{Ge}_{0.2} / \mathrm{Si}$ QDs [27]. Islands grown by liquid phase epitaxy are not taken into account in our study because they display higher aspect ratios $(\sim 0.5)$ [28]. We have thus calculated dark-field (220) TEM images of $\mathrm{D}_{2}$ domes for homogeneous compositions and for two types of composition variations. In the first type, a laterally constant composition is maintained in the $\mathrm{r}$ direction (Fig. 5a) whereas compositional gradients are introduced in the $\mathrm{z}$ direction either with a linear ("linear/linear" model) or S-shaped profile ("linear/S" model). In the second type, various models have been tested with parabolic contour lines in the $(\mathrm{r}, \mathrm{z})$ plane and linear dependence on the $\mathrm{z}$ axis ("parabolic/linear" model) (Fig. $5 b)$. The linear (S) dependence of indium composition $x$ as a function of $z$ is indicated in Fig. 5c (d).

\section{[Insert figure 5 about here]}

Fig. 6 shows calculated dark-field (220) TEM images of $\mathrm{Si}_{1-\mathrm{x}} \mathrm{Ge}_{\mathrm{x}} / \mathrm{Si}$ domes with the same geometrical characteristics as $\mathrm{D}_{2}$ domes and either with a homogeneous composition (with various values of germanium content $x$ ) (Fig. 6a) or with the models of compositional inhomogeneities defined in Fig. 5 (Fig. 6b-d). All the images have the same characteristics (i.e.black/white contrast and superimposed moiré-like fringes). $\mathrm{L}$ is defined as the distance between the centers of white and black lobes, and $\sigma$ is defined as the mean periodicity of moiré-like fringes (the periodicity of these fringes is not constant within any experimental or calculated images and that is why $\sigma$ has been defined as a mean periodicity). A $(\sigma, \mathrm{L} / \mathrm{b})$ diagram can be established for various homogeneous or heterogeneous compositions, and with the following parameters in the case of Fig.7: aspect ratio $\rho=0.20$, thin foil thickness $t=349 \mathrm{~nm}, \mathrm{~A}_{220}=0.0315$ (the anomalous absorption coefficient), $\xi_{220}^{\mathrm{e}}=62.7 \mathrm{~nm}$ (the effective extinction distance of $\mathrm{Si}_{0.5} \mathrm{Ge}_{0.5}$, calculated using the Vegard's law), $\mathrm{w}_{220}=-1,10$. It should be noted that moiré-like fringes are not found for low values of $\mathrm{x}(\mathrm{x}<\sim 0.4$ for homogenous composition and $\mathrm{x}_{1}$ or $\mathrm{x}_{\mathrm{S}}<\sim 0.6$ for heterogeneous compositions). The main result in this figure is that islands with a homogeneous composition can be theoretically unambiguously distinguished from islands with compositional inhomogeneity. However the experimental uncertainties on the measured values of $\sigma$ and $\mathrm{L} / \mathrm{b}$ (spread out in the rectangle in Fig.7) make it difficult to distinguish between islands with an homogeneous composition $\mathrm{x}=$ 0.4 and islands with a "parabolic/linear" heterogeneous composition.

\section{[Insert figure 6 about here]}

We have then considered the influence of the uncertainties with which the above parameters $\left(t, A_{220}, \xi_{220}^{\mathrm{e}}, \mathrm{w}_{220}\right.$ and $\rho$ ) can be determined. It is thereafter 
illustrated in the case of the $(\sigma, \mathrm{L} / \mathrm{b})_{\text {hom. }}$ points corresponding to homogeneous compositions.

\author{
[Insert figure 7 about here]
}

The anomalous absorption coefficients were respectively taken to be $\mathrm{A}_{220}=$ 0.0144 for $\mathrm{Si}$ and $\mathrm{A}_{220}=0.0485$ for $\mathrm{Ge}$ : these values were obtained from those calculated at $100 \mathrm{kV}$ [29] or $120 \mathrm{kV}$ [30] by extrapolating to $300 \mathrm{kV}$, using the analysis by Metherell and Whelan [31]. Vegard's law was used in the case of $\mathrm{Si}_{\mathrm{x}} \mathrm{Ge}_{1-\mathrm{x}}$ alloys.

\title{
[Insert figure 8 about here]
}

As an example, Fig. 8 shows the variations of $(\sigma, \mathrm{L} / \mathrm{b})_{\text {hom. }}$ points as a function of $\mathrm{A}_{220}$ varying in the range $0.0144(\mathrm{Si})-0.0485(\mathrm{Ge})$ : inspecting this figure shows that for any $\mathrm{Si}_{1-\mathrm{x}} \mathrm{Ge}_{\mathrm{x}} / \mathrm{Si}$ alloy, the positions of these points are rather insensitive to the uncertainties with which $\mathrm{A}_{220}$ can be calculated.

The influence of $w_{220}$ is depicted in Fig. 9. This figure shows that the experimental error in this parameter $( \pm 0.05)$ has little influence on the $(\sigma, \mathrm{L} / \mathrm{b})_{\text {hom. }}$ points, mainly through variations in $\mathrm{L}$.

\section{[Insert figure 9 about here]}

The effective extinction distances were respectively taken to be $\xi_{220}^{\mathrm{e}}=74.8 \pm$ $0.02 \mathrm{~nm}$ for $\mathrm{Si}$ and $\xi_{220}^{\mathrm{e}}=50.7 \pm 0.11 \mathrm{~nm}$ for Ge in keeping with the calculations of Doyle and Turner [32] or Lu et al [33]. The Vegard's law was used in the case of $\mathrm{Si}_{1-\mathrm{x}} \mathrm{Ge}_{\mathrm{x}} / \mathrm{Si}$ alloys. Calculations show that the positions of $(\sigma, \mathrm{L} / \mathrm{b})_{\text {hom. }}$ points are insensitive to the uncertainties with which $\xi_{220}^{\mathrm{e}}$ can be calculated.

\section{[Insert figure 10 about here] \\ [Insert figure 11 about here]}

Calculated dark-field (220) TEM contrasts were found to be very dependent on foil thickness t. Defining the moiré-like fringe contrast $C$ as $I_{2}-I_{1} / I_{2}+I_{1}$ where $I_{2(1)}$ is the intensity of the first dark (bright) fringe in the dark lobe, Fig. 10 shows, for instance in the $\mathrm{Si}$ case, that the variation of $\mathrm{C}$ as a function of $\mathrm{t}$ is periodic and with an approximate $\xi_{220}^{\mathrm{e}}$ period. Only experimental images with the highest contrasts $(>\sim 0.50)$ leading to precise measurements of $\sigma$ and $\mathrm{L}$, were considered, i.e. images corresponding to the range $330-360 \mathrm{~nm}$ for the 300 $380 \mathrm{~nm}$ period. The specimen thickness was measured in the vicinity of every studied QD and the location of the corresponding electron microprobe was | subsequently checked with the resulting contamination spot. As an example, for t $=349 \mathrm{~nm}$ situated in this range, Fig. 11 shows the variations of $(\sigma, \mathrm{L} / \mathrm{b})_{\mathrm{hom}}$. 
points corresponding to the uncertainty $\pm 4 \mathrm{~nm}$ with which $\mathrm{t}$ can be measured using conventional CBED analysis[34,35]. The influence of this uncertainty on $(\sigma, \mathrm{L} / \mathrm{b})_{\text {hom. }}$ points is found to be negligible.

[Insert figure 12 about here]

Fig. 12 shows the variations of $(\sigma, \mathrm{L} / \mathrm{b})_{\text {hom. }}$ points as a function of aspect ratio $(0.15<\rho<0.30)$. Examining this figure shows that for a homogeneous $\mathrm{x}=0.4$ composition, moiré-like fringes are not found with $\rho=0.15$, which is consistent with the fact that moiré-like fringes are never observed in the case of $\mathrm{D}_{1}$ domes. It should be noted that for any given composition $x, \sigma$ is very sensitive to the variations of $\rho$ and that it is thus important to determine the aspect ratio as accurately as possible. In the case of $\mathrm{D}_{2}$ domes, the effect of the uncertainty \pm 0.02 on the determination of $\rho$ is illustrated in Fig. 12 .

\section{DISCUSSION AND CONCLUSION}

The above analysis shows that all the parameters ( $\mathrm{t}, \mathrm{A}_{220}, \xi_{220}^{\mathrm{e}}, \mathrm{w}_{220}$ and $\rho$ ) influencing the contrast of moiré-like fringes can be measured or calculated with a sufficient precision and have thus little influence on the calculated values of $\sigma$ and L/b. However, the experimental uncertainties on the measured values of $\sigma$ and L/b (spread out in the rectangle in Fig.7-9 and 11-12) make it difficult to distinguish between islands with a homogeneous $\mathrm{x}=0.4$ composition and islands with a "parabolic/linear" heterogeneous composition. That is why an additional $\mathrm{x}$-ray energy dispersive spectrometry investigation has been performed [36] and it has shown that $\mathrm{D}_{2}$ domes have an approximately homogeneous $\mathrm{x}=0.4$ composition.

This result is consistent with those of Schülli et al [7] who have studied the influence of growth temperature on interdiffusion in uncapped $\mathrm{SiGe} / \mathrm{Si}$ islands grown by molecular beam epitaxy: the aspect ratio is found to be constant $(0.22)$ between 620 et $750^{\circ} \mathrm{C}$ and the maximum Ge content rapidly decreases from about 70 to $22 \%$ for growth temperatures between 620 and $800^{\circ} \mathrm{C}$ and is approximately $45 \%$ at $700^{\circ} \mathrm{C}$.

Our geometrical approach shows how it is possible to distinguish quantum dots with a homogeneous composition from those with compositional inhomogeneity. However this does not make it possible to choose between various compositional variations and precise determination of these variations should take account of the relative intensities of black/white lobes and of moiré-like fringes.

\section{ACKNOWLEDGEMENTS}

This work was partially supported by the French "Région Nord-Pas de Calais", by the European FEDER ("Fonds Européen de Développement Régional") and the "Action Concertée Nanosciences/Nanotechnologies". Many thanks are due to 
Drs D. Bouchier and L.H. Nguyen (Institut d'Electronique Fondamentale, Orsay, France) for providing the $\mathrm{SiGe} / \mathrm{Si}$ samples.

\section{REFERENCES}

[1] K. Leonardi, H. Heinke, K. Okhawa, D. Hommel, H. Selke, F. Gindele and U. Woggon, Appl. Phys. Lett. 71, 1510 (1997).

[2] M. Tomitori, K. Watanabe, M. Kobayashi and O. Nishikawa, Appl. Surf. Sci. 76/77, 322 (1994).

[3] G. Medeiros-Ribeiro, A.M. Bratkowski, T.I. Kamins, D.A. Ohlberg and R.S. Williams, Science 279, 353 (1998).

[4] S.A. Chaparro, Y. Zhang, J. Drucker, D. Chandrasekhar and D.J. Smith, J. Appl. Phys. 87, 2245 (2000).

[5] M. Hanke, M. Schmidbauer, R. Köhler, F. Syrowatka, A.K. Gerlitzke and T. Boeck, Appl. Phys. Lett. 84, 5228 (2004).

[6] A. Malachias, S. Kycia, G. Medeiros-Ribeiro, R. Magalhaes-Paniago, T.I. Kamins and R. S. Williams, Phys. Rev. Lett. 91, 176101 (2003).

[7] T.U. Schülli, M. Stoffel, A. Hesse, J. Stangl, R.T. Lechner, E. Wintersberger, M. Sztucki, T.H. Metzger, O.G. Schmidt and G. Bauer, Phys. Rev. B 71, 35326 (2005).

[8] A. V. Kolobov, H. Oyanagi, S. Wei, K. Brunner, G. Abstreiter and K. Tanaka, Phys. Rev. B 66, 75319 (2002).

[9] U. Denker, M. Stoffel and O.G. Schmidt, Phys. Rev. Lett. 90, 196102 (2003).

[10] N. Liu, J. Tersoff, O. Blakenov, A. L. Holmes, Jr. and C.K. Shih, Phys. Rev. Lett. 84, 334 (2000).

[11] A. Rosenauer, U. Fischer, D. Gerthsen and A. Förster, Appl. Phys. Lett. 71, 3868 (1997).

[12] T. Walther, C.J. Humphreys and A. G. Cullis, Appl. Phys. Lett. 71, 809 (1997). 
[13] M. Floyd, Y. Zang, K.P. Driver, J. Drucker, P.A. Crozier and D.J. Smith, Appl. Phys. Lett. 82, 1473 (2003).

[14] H. Kirmse, R. Schneider, R. Otto, W. Neumann, M. Hanke, M. Schmidbauer, R. Köhler, H. Wawra, T. Boeck, I.P. Soshnikov, N.N. Ledentsov, Z.N. Krasilnik and A. Novikov, Inst. Phys. Conf. Ser. No 180, 115 (2004).

[15] S.A. Chaparro, J. Drucker, Y. Zhang, D. Chandrasekhar, M.R. Mc Cartney and D.J. Smith, Phys. Rev. Lett. 83, 1199 (1999).

[16] X.Z. Liao, J. Zou, X.F. Duan, D.J.H. Cockayne, Z.M. Jiang, X. Wang and R. Leon, Appl. Phys. Lett. 77, 1304 (2000).

[17] X.Z. Liao, J. Zou, D.J.H. Cockayne, Z.M. Jiang, and X. Wang, J. Appl. Phys. 90, 2725 (2001).

[18] Y. Androussi, D. Ferré and A. Lefebvre, Appl. Surf. Sci. 117, 258 (2001).

[19] Y. Androussi, T. Benabbas and A. Lefebvre, Ultramicr. 93, 161 (2002).

[20] Y. Androussi, T. Benabbas, D. Jacob and A. Lefebvre, Inst. Phys. Conf. Ser. No 180, 95 (2004).

[21] P.D. Miller, C.P. Liu, W.L. Henstrom, J.M. Gibson, D.G. Cahill, Y. Huang, P. Zhang, T.I. Kamins, D.P. Basile and R.S. Williams, Appl. Phys. Lett. 75, 46 (1999).

[22] P.D. Miller, C.P. Liu and J.M. Gibson, Ultramicr. 84, 225 (2000).

[23] P. Boucaud, V. Le Thanh, V. Yam, S. Sauvage, N. Meneceur, M. Elkurdi, D. Débarre and D. Bouchier, Mat. Sci. Eng. B 89, 36 (2002).

[24] P.B. Hirsch, A. Howie, R.B. Nicholson, R.B. Pashley and M.J. Whelan, Electron Microscopy of Thin Crystal (Butterworths, London, 1977).

[25] T. Benabbas, P. François, Y. Androussi and A.Lefebvre A, J. Appl. Phys. 80, 2763 (1996).

[26] K.H. Katerbau, Phil. Mag. 43, 409 (1981).

[27] J.A. Floro, E. Chason, L.B. Freund, R.D. Twesten, R.Q. Hwang and G.A. Lucadamo, Phys. Rev. B59, 1990 (1999). 
[28] M. Hanke, M. Schmidbauer, R. Köhler, F. Syrowatka, A.K. Gerlitzke and T. Boeck, Appl. Phys. Lett. 84, 5228 (2004).

[29] G. Radi, Acta Cryst. A26, 41 (1970).

[30] S. Swaminathan, S. Altynov, I.P. Jones, N.J. Zaluzec, D.M. Maher and H.L. Fraser, Ultramicr. 69, 169 (1997).

[31] J.F. Metherell and M.J. Whelan, Phil. Mag. 15, 755 (1967).

[32] P.A. Doyle and P.S. Turner, Acta Cryst. A24, 390 (1968).

[33]Z.W. Lu, A. Zunger and M. Deutsch, Phys. Rev. B47, 9385 (1993).

[34] P.M. Kelly, A. Jostsons, A.G. Blake and J.G. Napier, Phys. Stat. Sol (a) 31, 771 (1975).

[35] D. Delille, R. Pantel and E. Van Cappellen, Ultramicr. 87, 5 (2001).

[36] D. Brouri, J.Y. Laval, M. Zak and C. Delamarre, unpublished results. 


\begin{tabular}{|c|c|c|}
\hline $\begin{array}{c}\text { Growth } \\
\text { temperature }\left({ }^{\circ} \mathrm{C}\right)\end{array}$ & $\mathrm{b}(\mathrm{nm})$ & $\mathrm{h}(\mathrm{nm})$ \\
\hline 600 & $100\left(\mathrm{D}_{1}\right)$ & $15\left(\mathrm{D}_{1}\right)$ \\
\hline 700 & $110\left(\mathrm{D}_{2}\right)$ & $22\left(\mathrm{D}_{2}\right)$ \\
& $100(\mathrm{P})$ & $12(\mathrm{P})$ \\
\hline
\end{tabular}

Table 1: Average sizes of domes $\left(\mathrm{D}_{1}\right.$ and $\left.\mathrm{D}_{2}\right)$ and pyramidal islands $(\mathrm{P})$ for various growth temperatures $; \mathrm{b}=\mathrm{b}$ ase, $\mathrm{h}=$ height. 


\begin{tabular}{|c|c|c|}
\hline & $\begin{array}{c}\text { Electron entrance } \\
\text { surface }\end{array}$ & $\begin{array}{c}\text { Electron exit } \\
\text { surface }\end{array}$ \\
\hline Bright field & + & + \\
$\mathrm{w}>0$ & - & - \\
$\mathrm{w}<0$ & - & + \\
Dark field & - & - \\
$\mathrm{w}>0$ & + & \\
$\mathrm{w}<0$ & & \\
\hline
\end{tabular}

Table 2: Enhancement (+) or reduction (-) of dynamical TEM contrast for lattice defects near the specimen surfaces.

Figure captions 
Figure 1: Schematic view of the dome-shaped islands used for the FE calculations and for the TEM contrast simulations.

Figure 2: Tapping mode $(1.2 \mu \mathrm{m} \times 1.2 \mu \mathrm{m})$ image of $\mathrm{Si}_{1-\mathrm{x}} \mathrm{Ge}_{\mathrm{x}} / \mathrm{Si}$ QDs grown at $700^{\circ} \mathrm{C}$. A few pyramidal (dome-shaped) QDs are indicated with black (white) arrows.

Figure 3: Experimental dark-field (220) TEM image of $\mathrm{D}_{1}$ dome-shaped $\mathrm{Si}_{1}$ ${ }_{\mathrm{x}} \mathrm{Ge}_{\mathrm{x}} / \mathrm{Si} \mathrm{QDs}$ grown at $600^{\circ} \mathrm{C} ; \mathrm{w}_{220}=-1.10$.

Figure 4: Experimental dark-field (220) TEM image of $\mathrm{Si}_{1-\mathrm{x}} \mathrm{Ge}_{\mathrm{x}} / \mathrm{Si}$ QDs grown at $700^{\circ} \mathrm{C} ; \mathrm{w}_{220}=-1.10, \mathrm{t}=349 \mathrm{~nm} .(\mathrm{a})$ : a pyramid $(\mathrm{P})$ and two domes $\left(\mathrm{D}_{2}\right.$ and $\left.\mathrm{D}_{2}{ }_{2}\right)$. Only the domes display moiré-like fringes. (b): enlargement of the $\mathrm{D}_{2}$ dome.

Figure 5: Various models of compositional inhomogeneity. (a): linear variation in the $(r, z)$ plane. (b): parabolic variation in the $(r, z)$ plane. (c): linear dependence of germanium composition $\mathrm{x}$ as a function of $\mathrm{z}$ and for $\mathrm{r}=0 .(\mathrm{d}): \mathrm{S}$ Deleted: indium dependence of germanium composition $\mathrm{x}$ as a function of $\mathrm{z}$ and for $\mathrm{r}=0$.

Deleted: indium Figure 6: Calculated dark-field (220) TEM images of dome-shaped $\mathrm{Si}_{1-\mathrm{x}} \mathrm{Ge}_{\mathrm{x}} / \mathrm{Si}$ QDs with a homogeneous composition (a), or with various compositional inhomogeneities: linear/linear model (b), linear/S model (c), parabolic/linear 
model $(\mathrm{d})$. Aspect ratio $\rho=0.20, \mathrm{t}=349 \mathrm{~nm}, \mathrm{~A}_{220}=0.0315, \quad \xi_{220}^{\mathrm{e}}=62.7 \mathrm{~nm}$, $\mathrm{w}_{220}=-1,10$.

Figure 7: Calculated $(\sigma, \mathrm{L} / \mathrm{b})$ diagram for dome-shaped $\mathrm{Si}_{1-\mathrm{x}} \mathrm{Ge}_{\mathrm{x}} / \mathrm{Si}$ QDs, either with homogeneous compositions and various $\mathrm{x}$ silicon contents $(\bullet)$ or with compositional inhomogeneities: $(\boldsymbol{\square})=$ linear/linear model; $(\boldsymbol{\Delta})=$ linear/S model; $(\square)=$ parabolic/linear model. Aspect ratio $\rho=0.20, t=349 \mathrm{~nm}, \mathrm{~A}_{220}=0.0315$, $\xi_{220}^{\mathrm{e}}=62.7 \mathrm{~nm}, \mathrm{w}_{220}=-1,10$. Experimental points corresponding to the measured values $\sigma$ and $L / b$ are spread out into the rectangle located in the upper part of the figure.

Figure 8: Variations of $(\sigma, \mathrm{L} / \mathrm{b})_{\text {hom. }}$ points as a function of $\mathrm{A}_{220}$. Aspect ratio $\rho=$ $0.20, \mathrm{t}=349 \mathrm{~nm}, \xi_{220}^{\mathrm{e}}=62.7 \mathrm{~nm}, \mathrm{w}_{220}=-1,10$. The rectangle located in the upper part is the same as in Fig.7.

Figure 9: Variations of $(\sigma, \mathrm{L} / \mathrm{b})_{\text {hom. }}$ points for various values of $\mathrm{w}_{220}$ corresponding to the experimental uncertainties. Aspect ratio $\rho=0.20, t=349$ $\mathrm{nm}, \mathrm{A}_{220}=0.0315, \xi_{220}^{\mathrm{e}}=62.7 \mathrm{~nm}$. The rectangle located in the upper part is the same as in Fig.7. 
Figure 10: Moiré-like fringe contrast $\mathrm{C}$ as a function of the foil thickness $\mathrm{t}$. Aspect ratio $\rho=0.20, \mathrm{~A}_{220}=0.0315, \xi_{220}^{\mathrm{e}}=62.7 \mathrm{~nm}, \mathrm{w}_{220}=-1,10$.

Figure 11: Variations of $(\sigma, L / b)_{\text {hom.. }}$ points for various values of $t$ ranging from 345 to $353 \mathrm{~nm}$. Aspect ratio $\rho=0.20, \mathrm{~A}_{220}=0.0315, \xi_{220}^{\mathrm{e}}=62.7 \mathrm{~nm}, \mathrm{w}_{220}=-$ 1,10. The rectangle located in the upper part is the same as in Fig.7.

Figure 12: Variations of $(\sigma, L / b)_{\text {hom. }}$ points for various values of $\rho$ ranging from 0.15 to $0.30:(\bullet) \rho=0.15 ;(\boldsymbol{\square}) \rho=0.20 ;(\boldsymbol{\Delta}) \rho=0.25 ;(\bullet) \rho=0.30 . \quad \mathrm{A}_{220}=$ $0.0315, \xi_{220}^{\mathrm{e}}=62.7 \mathrm{~nm}, \mathrm{w}_{220}=-1,10, \mathrm{t}=349 \mathrm{~nm}$. The rectangle located in the upper part is the same as in Fig.7. The effect of the uncertainty \pm 0.02 with which $\rho=0.20$ can be measured is illustrated with dotted rectangles. 
Figure 1 


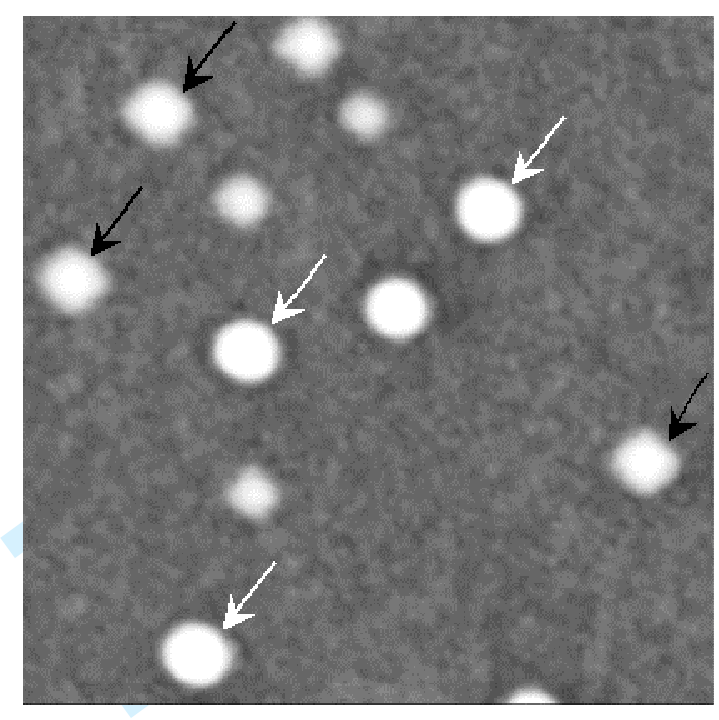

Figure 2 
Figure 3 
b

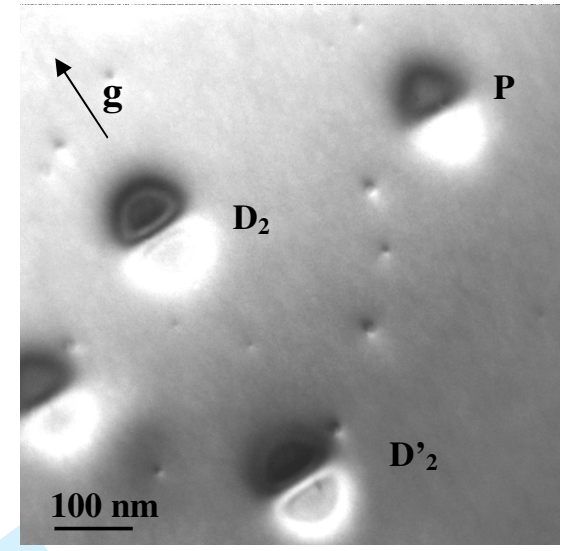

a

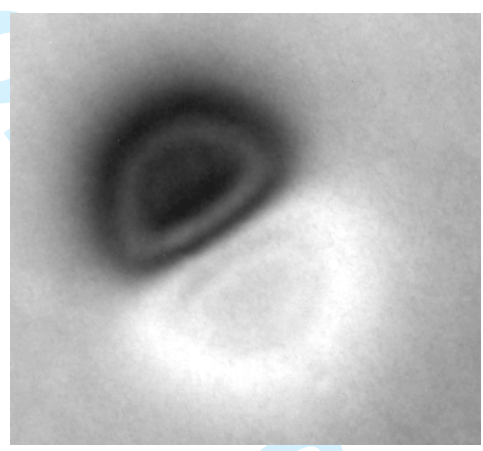

Figure 4 
a
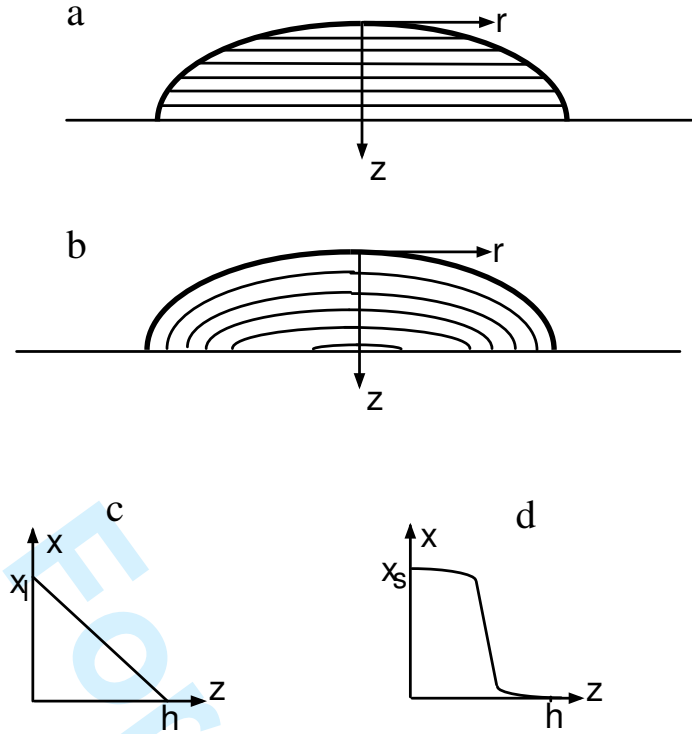

Figure 5 

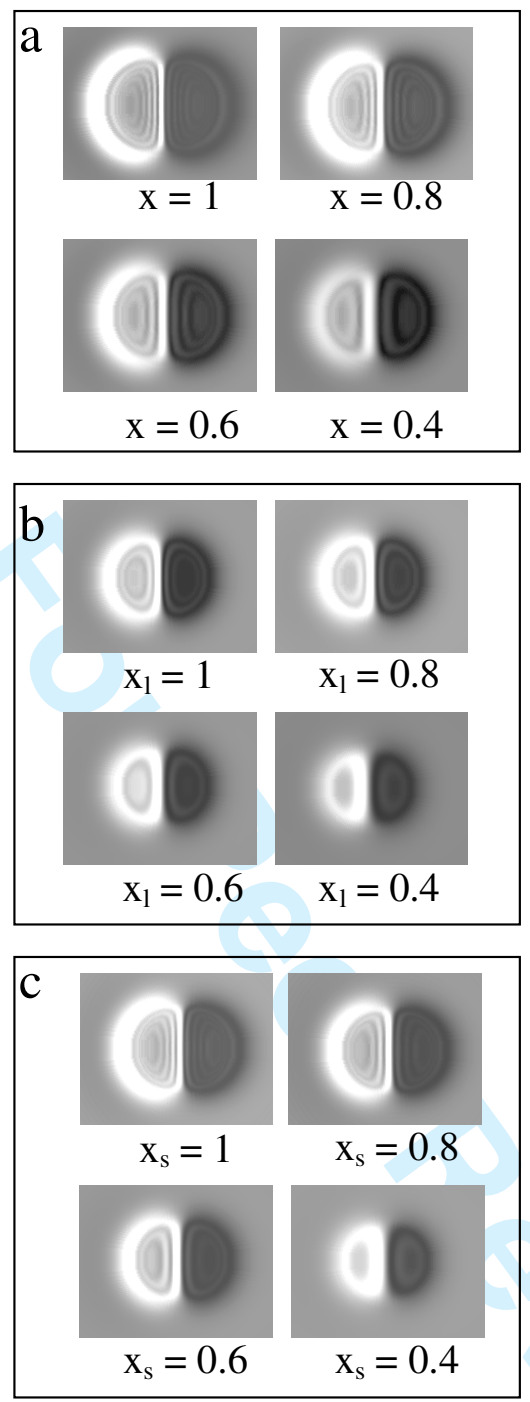

Figure 6

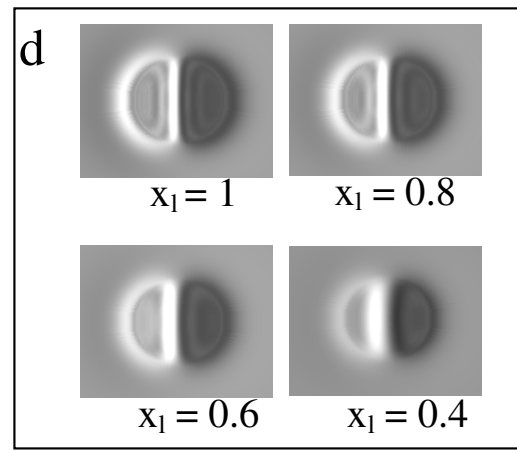

$\underline{100 \mathrm{~nm}}$ 
Figure 7 


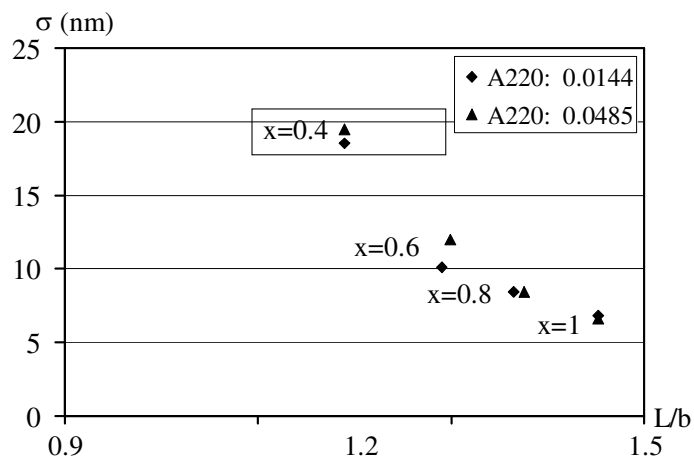

Figure 8 
Figure 9

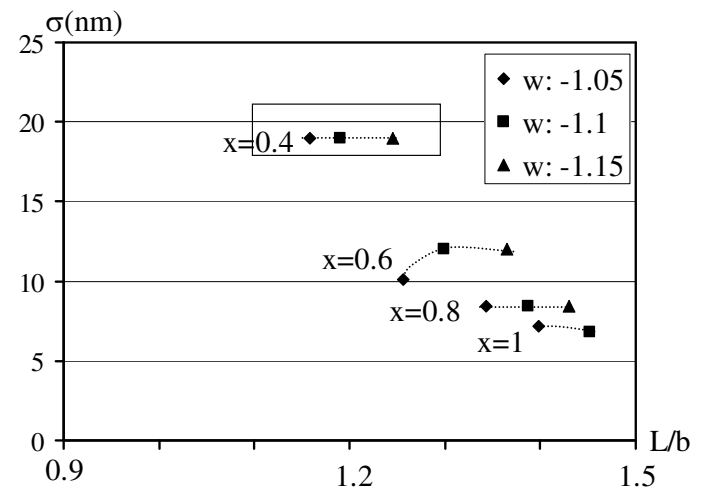

\section{Figure}




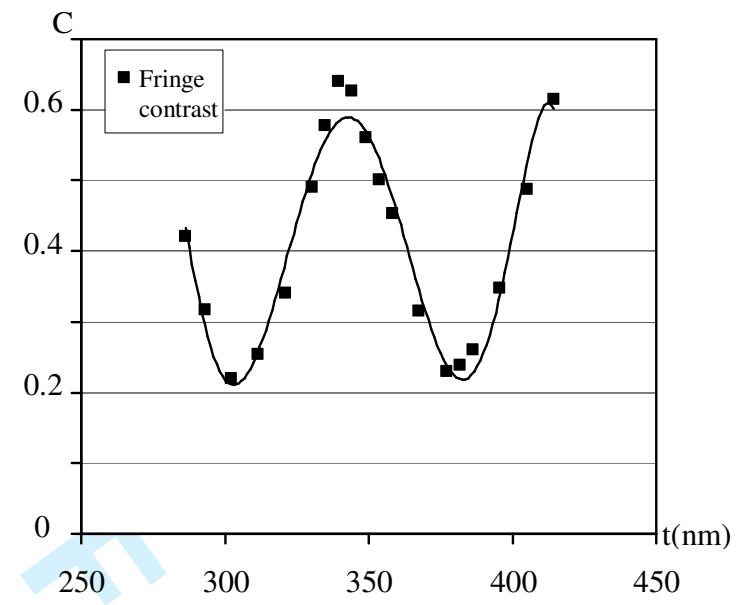

Figure 10 
Figure 11

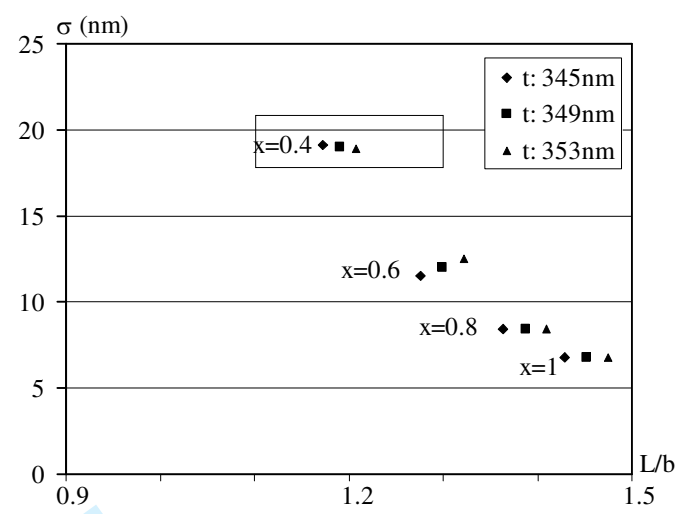

Figure 11 


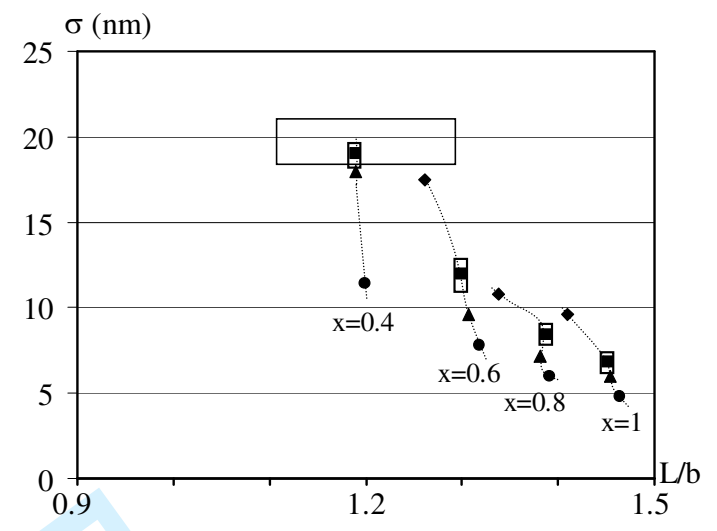

Figure 12 